\title{
Chlamydia trachomatis in women attending a gynaecological outpatient clinic with lower genital tract infection
}

\author{
L SVENSSON,* L WESTRÖM,* AND P-A MÅRDH† \\ From the *Department of Obstetrics and Gynaecology, University Hospital, and the +Institute of Medical \\ Microbiology, University of Lund, Lund, Sweden
}

SUMMARY In a study of 3794 consecutive women attending a gynaecological outpatient clinic with symptoms of lower genital tract infection (LGTI) $350(9 \cdot 2 \%)$ harboured Chlamydia trachomatis and $83(2 \cdot 2 \%)$ Neisseria gonorrhoeae. One hundred and ninety-five patients who were later found to have acute salpingitis and 109 other women in whom the chlamydial cultures were spoiled were excluded from the series. Of the remaining 3490 women, 281 were infected with $C$ trachomatis, 42 with $N$ gonorrhoeae, and 17 with both. Of the 3150 women who were infected with neither organism, 146 were randomly selected as controls.

The chlamydia-positive patients were younger $(\mathrm{P}<0 \cdot 001)$, did not complain of pelvic discomfort or pain $(\mathrm{P}<0.01)$, and used oral contraceptives $(\mathrm{P}<0.001)$ more frequently than did the controls; intrauterine devices were used more often $(P<0.01)$ by the controls. Increased vaginal discharge was reported significantly more often in chlamydia-positive patients than in the controls $(\mathrm{P}<0 \cdot 05)$. Of 266 women harbouring $C$ trachomatis the organism was still present in $22(8 \cdot 3 \%)$ when they were followed up from two to more than eight weeks after finishing treatment with doxycycline.

Of 91 male consorts of chlamydia-positive women, $53(58 \cdot 2 \%)$ were infected with $C$ trachomatis.

\section{Introduction}

Chlamydia trachomatis and Neisseria gonorrhoeae are the most important aetiological agents of sexually transmitted diseases (STD) in Sweden. The prevalence of genital $C$ trachomatis infection in Swedish women attending STD clinics ${ }^{12}$ and gynaecological clinics for health checks, ${ }^{1}$ applying for legal abortion, ${ }^{3}$ seeking contraceptive advice, ${ }^{1}$ and attending gynaecological outpatient clinics with signs of lower genital tract infection (LGTI) ${ }^{4}$ has varied between $5 \%$ and $25 \%$. Serological studies have indicated that at least half of all cases of acute salpingitis in southern Sweden are associated with chlamydial infection..$^{5}$

Oral administration of tetracycline for 7-21 days has proved useful in treating chlamydial cervicitis. ${ }^{4} 7$

The aims of this study were to determine the prevalence of chlamydial cervicitis in women with

Address for reprints: Dr L Svensson, Department of Obstetrics and Gynaecology, University Hospital, S-221 85 Lund, Sweden

Accepted for publication 9 January 1981 symptoms of LGTI attending a gynaecological outpatient clinic, the effect of doxycycline treatment on the isolation of $C$ trachomatis, and the results of contact tracing in chlamydia-positive cases.

\section{Patients and methods}

\section{STUDY POPULATION}

A total of 3794 women, who attended the outpatient clinic at the department of obstetrics and gynaecology, University Hospital, Lund, Sweden, from October 1977 to December 1978 was studied. All complained of one or more symptoms suggesting genital tract infection: pelvic discomfort or pain, increased or foul-smelling vaginal discharge, itching or burning, frequency or pain at voiding or both.

From this total, 195 women were excluded when acute salpingitis was diagnosed and 109 because the presence of $C$ trachomatis could not be established either on account of a non-specific cytopathogenic effect induced in the McCoy cell cultures by the specimens or because of technical errors.

The remaining 3490 patients were divided into four groups. 
Group 1 consisted of 281 women from whom $C$ trachomatis was isolated from the cervix.

Group 2 consisted of 42 women infected with $N$ gonorrhoeae but not with $C$ trachomatis.

Group 3 consisted of 17 women infected with both $C$ trachomatis and $N$ gonorrhoeae.

Group 4 consisted of 146 patients who attended consecutively during two periods totalling five weeks and were selected randomly from the $\mathbf{3 1 5 0}$ women in whom neither chlamydial nor gonococcal infections were diagnosed.

SAMPLING AND CULTURE

Samples for the isolation of $C$ trachomatis were collected by rotating a sterile cotton-tipped swab in the cervical canal. The specimens were transported in 2-SP as described. ${ }^{4}$ Cycloheximide-treated McCoy cells were used. ${ }^{8}$

Specimens for the culture of $N$ gonorrhoeae were collected from the cervical canal, the urethra, and the rectum with cottonwool-tipped swabs and inoculated directly on to hematin agar plates. ${ }^{9} \mathrm{~N}$ gonorrhoeae was identified as described. ${ }^{9}$

\section{CLINICAL HISTORY}

Information was obtained on present symptoms, age, earlier pregnancies, previous episodes of LGTI or salpingitis, and present contraceptive methods.

TREATMENT AND FOLLOW UP

Women with gonococcal infection were treated with either $200 \mathrm{mg}$ doxycycline on the first day, followed by $100 \mathrm{mg}$ daily for eight days, or with $1.5 \mathrm{~g}$ pivampicillin and $1 \mathrm{~g}$ probenecid in a single dose. Patients infected with both $C$ trachomatis and $N$ gonorrhoeae and those in whom a chlamydial but not a gonococcal infection was diagnosed were treated with $200 \mathrm{mg}$ doxycycline on the first day followed by $100 \mathrm{mg}$ daily for 5-13 days.

Patients with gonorrhoea were followed up at the STD clinic, University Hospital, Lund; those with chlamydial infection and those with both chlamydial and gonococcal infections were requested to return to the gynaecological outpatient clinic for follow up at intervals from two to more than eight weeks after finishing treatment.

Male consorts of chlamydia-positive women were requested to attend the STD clinic.

\section{STATISTICAL METHODS}

Student's $\boldsymbol{t}$ test, the $\boldsymbol{x}^{2}$ test with Yates's correction, and Fisher's exact test were used.

\section{Results}

CULTURE

$C$ trachomatis was isolated from $350(9 \cdot 2 \%)$ and $N$
TABLE I Age distribution of women with lower genital tract infection with Chlamydia trachomatis (group 1), or on Neisseria gonorrhoeae (group 2), or both (group 3) and of $\Rightarrow$ controls (group 4)

\begin{tabular}{|c|c|c|c|c|}
\hline \multirow[b]{2}{*}{$\begin{array}{l}\text { Age } \\
\text { (years) }\end{array}$} & \multicolumn{4}{|c|}{$\%$ of women in: } \\
\hline & $\begin{array}{l}\text { Group } 1 \\
(n=281)\end{array}$ & $\begin{array}{l}\text { Group } 2 \\
(n=42)\end{array}$ & $\begin{array}{l}\text { Group } 3 \\
(n=17)\end{array}$ & $\begin{array}{l}\text { Group } 4 \\
(n=146)\end{array}$ \\
\hline $\begin{array}{l}\leqslant 19 \\
20-24 \\
25-29 \\
30-34 \\
35-39 \\
40-44 \\
\geqslant 45\end{array}$ & $\begin{array}{r}28 \cdot 1 \\
39 \cdot 1 \\
15 \cdot 3 \\
10 \cdot 0 \\
5 \cdot 3 \\
1 \cdot 1 \\
1 \cdot 1\end{array}$ & $\begin{array}{r}21 \cdot 4 \\
35 \cdot 7 \\
21 \cdot 4 \\
11 \cdot 9 \\
7 \cdot 2 \\
0 \cdot 0 \\
2 \cdot 4\end{array}$ & $\begin{array}{r}35 \cdot 3 \\
35 \cdot 3 \\
23 \cdot 5 \\
5 \cdot 9 \\
0 \cdot 0 \\
0 \cdot 0 \\
0 \cdot 0\end{array}$ & $\begin{array}{r}15 \cdot 1 \\
27 \cdot 4 \\
28 \cdot 8 \\
17 \cdot 1 \\
6 \cdot 2 \\
2 \cdot 7 \\
2 \cdot 7\end{array}$ \\
\hline Mean & $23 \cdot 7 \pm 6 \cdot 5$ & $24 \cdot 8 \pm 6 \cdot 5$ & $21 \cdot 6 \pm 4 \cdot 2$ & $26 \cdot 6 \pm 7 \cdot 3$ \\
\hline
\end{tabular}

gonorrhoeae from $83(2 \cdot 2 \%)$ of the 3794 women of studied. Seventeen $(0 \cdot 4 \%)$ of the 3794 patients were 으 infected with both chlamydia and gonococci.

\section{AGE DISTRIBUTION}

The age distribution of the women in the four groups $\oplus$ is shown in table I. The chlamydia-infected women (groups 1 and 3) were significantly $(P<0.001)$ younger than the controls (group 4). Those who had both chlamydial and gonococcal infections were younger than those who had only gonorrhoea $(\mathrm{P}<0 \cdot 05)$.

\section{CLINICAL HISTORY}

Data on previous history, symptoms, and con- $\overrightarrow{\vec{\partial}}$ traceptive methods are given in table II. No 3 significant differences were found between the

TABLE II Clinical history, symptoms, and contraceptive method in women infected with Chlamydia trachomatis (group 1), or Neisseria gonorrhoeae (group 2), or both (group 3) and in controls (group 4)

\begin{tabular}{|c|c|c|c|c|}
\hline \multirow[b]{2}{*}{ Clinical data } & \multicolumn{4}{|c|}{$\%$ of women in: } \\
\hline & $\begin{array}{l}\text { Group } 1 \\
(n=281)\end{array}$ & $\begin{array}{l}\text { Group } 2 \\
(n=42)\end{array}$ & $\begin{array}{l}\text { Group } 3 \\
(n=17)\end{array}$ & $\begin{array}{l}\text { Group } 4 \\
(n=146)\end{array}$ \\
\hline $\begin{array}{l}\text { Previous pregnancy } \\
\text { Previous LGTI } \\
\text { Previous salpingitis } \\
\text { Pelvic discomfort }\end{array}$ & $\begin{array}{r}47 \cdot 0 \\
43 \cdot 4 \\
7 \cdot 8\end{array}$ & $\begin{array}{l}47 \cdot 6 \\
28 \cdot 6 \\
16 \cdot 7\end{array}$ & $\begin{array}{r}52 \cdot 9 \\
41 \cdot 2 \\
5 \cdot 9\end{array}$ & $\begin{array}{l}58 \cdot 9 \\
37 \cdot 7 \\
13 \cdot 7\end{array}$ \\
\hline $\begin{array}{l}\text { or pain } \\
\text { Increased vaginal }\end{array}$ & $57 \cdot 3$ & $69 \cdot 0$ & $76 \cdot 5$ & $71 \cdot 2$ \\
\hline $\begin{array}{l}\text { discharge } \\
\text { Foul-smelling yaginal }\end{array}$ & $69 \cdot 8$ & $73 \cdot 8$ & $76 \cdot 5$ & $58 \cdot 2$ \\
\hline $\begin{array}{l}\text { discharge } \\
\text { Itching or burning }\end{array}$ & $\begin{array}{l}14 \cdot 2 \\
10 \cdot 6\end{array}$ & $\begin{array}{l}11 \cdot 9 \\
11 \cdot 9\end{array}$ & $\begin{array}{r}17 \cdot 6 \\
0 \cdot 0\end{array}$ & $\begin{array}{l}14 \cdot 4 \\
18 \cdot 5\end{array}$ \\
\hline $\begin{array}{l}\text { Frequency or pain on } \\
\text { voiding or both } \\
\text { Irregular bleeding }\end{array}$ & $\begin{array}{l}10 \cdot 3 \\
32 \cdot 0\end{array}$ & $\begin{array}{l}19 \cdot 0 \\
21 \cdot 4\end{array}$ & $\begin{array}{l}35 \cdot 3 \\
41 \cdot 2\end{array}$ & $\begin{array}{r}8 \cdot 2 \\
28 \cdot 1\end{array}$ \\
\hline $\begin{array}{l}\text { Contraceptive method } \\
\text { Oral contraceptive } \\
\text { Intrauterine device } \\
\text { Other or none }\end{array}$ & $\begin{array}{l}49 \cdot 8 \\
20 \cdot 3 \\
29 \cdot 9\end{array}$ & $\begin{array}{l}40 \cdot 5 \\
21 \cdot 4 \\
38 \cdot 1\end{array}$ & $\begin{array}{l}41 \cdot 2 \\
29 \cdot 4 \\
29 \cdot 4\end{array}$ & $\begin{array}{l}27 \cdot 4 \\
32 \cdot 9 \\
39 \cdot 7\end{array}$ \\
\hline
\end{tabular}


patients with gonorrhoea alone and the women in the other three groups (table II). The patients in groups 1 and 4 reported itching or burning or both more often than those in group $3(P=0.022$ and $P=0.038$ respectively). The women in group 3 complained of frequency or pain on voiding or both significantly more often than those in groups 1 and $4(P=0.0071$ and $P=0.45$ respectively). The patients in group 1 differed from those in group 4 in several respects: the women in group 1 had been pregnant significantly less often $(\mathrm{P}<0 \cdot 05)$, complained of pelvic discomfort or pain less often $(P<0 \cdot 01)$, and had increased vaginal discharge more often $(P<0.05)$ than those in group 4.

Although all the patients studied complained of symptoms that suggested LGTI such an infection was diagnosed in only $221(78 \cdot 6 \%), 33(78 \cdot 6 \%), 13$ $(76 \cdot 5 \%)$, and $100(68 \cdot 5 \%)$ women in groups $1,2,3$, and 4 respectively. The difference between groups 1 and 4 was significant $(P<0.05)$

Oral contraceptives were used more frequently by the patients in group 1 than by those in group 4 $(P<0.001)$; the opposite was found in the use of intrauterine devices (IUD) $(\mathrm{P}<0 \cdot 01)$ (table II). There were no differences between the two groups in the use of other contraceptive methods.

\section{AGE-RELATED CORRELATIONS}

When patients in the same age group are compared no significant difference was found in the frequency of chlamydial infection between women who had or never had been pregnant. Women in group 1 under 25 years of age had been treated previously for LGTI significantly $(\mathrm{P}<0.01)$ more of ten than those in group $4(46 \%$ and $25 \cdot 8 \%$ respectively). In the women aged between 20 and 24 years complaints of increased vaginal discharge were significantly $(\mathrm{P}<0.05)$ more common in group $1(73.6 \%)$ than in group $4(55 \%)$. Pelvic discomfort or pain was significantly $(\mathrm{P}<0.01)$ more common in group $4(83.3 \%)$ than in group 1 $(48 \cdot 3 \%)$ in women aged between 25 and 29 years.

\section{TREATMENT}

The results of treatment of patients with chlamydial infections with doxycycline are shown in table III.

TABLE III Result of doxycycline treatment in women with Chlamydia trachomatis infection

\begin{tabular}{llll}
\hline $\begin{array}{l}\text { Control culture } \\
\text { (weeks after end } \\
\text { of treatment) }\end{array}$ & No of patients & $\begin{array}{l}\text { Culture not } \\
\text { performed or } \\
\text { spoiled }\end{array}$ & $\begin{array}{l}\text { \% Culture- } \\
\text { positive }\end{array}$ \\
\hline$<4$ & 135 & 17 & $1 \cdot 5$ \\
$4-8$ & 90 & 5 & $2 \cdot 2$ \\
$>8$ & 41 & 5 & $43 \cdot 9$ \\
Total & 266 & 27 & $8 \cdot 3$ \\
\hline
\end{tabular}

Thirteen women infected with both $C$ trachomatis and $N$ gonorrhoeae and 37 patients with acute salpingitis are included in the figures. Of the 148 patients treated with doxycycline for 6-7 days, 111 returned for follow up, and of the 202 women treated for 9-14 days 155 returned for follow up. There was no difference in the results of these treatment schedules; eight $(7 \cdot 2 \%)$ of the 111 patients given the shorter course and $14(9 \%)$ of the 155 patients given the longer course were culture-positive at follow up.

\section{CONTACT TRACING}

Of the 91 maie consorts who were examined at the STD clinic, $53(58 \cdot 2 \%)$ harboured $C$ trachomatis in the urethra.

\section{Discussion}

In different series of gynaecological patients the isolation rate for $C$ trachomatis has varied between $8 \%$ and $12 \%{ }^{10-12}$ In women with objective signs of LGTI (variously defined) the corresponding figures have been $17-19 \% .^{413}$ The comparatively low isolation rate in this study $(\mathbf{9 \cdot 2 \%})$ might be due to less strict criteria for the diagnosis of LGTI, so that our series included many women who were not infected. Another explanation for differences in the isolation rate between various series is a difference in the age distribution of the patients studied. Thus, the present as well as earlier studies ${ }^{13}$ show that $C$ trachomatis infection in women with cervicitis occurs more often in younger age groups. Women with chlamydia-associated salpingitis are also significantly younger than patients with non-chlamydial or nongonococcal salpingitis. ${ }^{15}$

Of the patients in our study who were subsequently found to have acute salpingitis, $52(26.5 \%)$ of 195 harboured $C$ trachomatis in the cervix. Serological studies suggested, however, that at least twice as many of these cases were associated with a chlamydial infection. ${ }^{56}$ of the 350 women with symptoms of LGTI and who were culture-positive for $C$ trachomatis, $14.9 \%$ had acute salpingitis. The corresponding figure for the 83 women with gonorrhoea was $27 \cdot 5 \%$. These figures include the few women who were infected with both organisms.

Women with chlamydial LGTI attending STD clinics have the same symptoms and signs (except for cervical ectopy) as other patients with cervicitis not associated with this organism. ${ }^{14}$ In our study increased vaginal discharge was more common in the chlamydia-positive women than in the controls. However, when only the women with clinical LGTI were analysed, no such difference was found. The difference in pelvic discomfort or pain between the chlamydia-positive patients and the controls was 
significant, whether patients with symptoms or symptoms and signs of LGTI were compared.

Several studies ${ }^{16} 17$ have shown that women infected with $C$ trachomatis used oral contraceptives more often than did the controls, whereas others 1418 report no such relationship. In none of these studies, however, was the age distribution of the patients considered. In our study there was no difference in the culture results and the use of oral contraceptives among teenagers, but in women over 20 years of age oral contraceptives were used significantly more often by the chlamydia-positive patients than by the controls.

IUDs were used significantly more often by the controls than by the chlamydia-positive patients in the over-20 age group (regardless of whether or not they had signs of LGTI). All IUDs used by the women in the present study were copper-coated. It is noteworthy that copper ions decrease the inclusion count of $\boldsymbol{C}$ trachomatis in experimentally infected McCoy cell cultures. ${ }^{19}$

Doxycycline treatment for six or seven days was as effective as that given for up to 14 days. In those women who were culture-positive for $C$ trachomatis when investigated more than eight weeks after finishing treatment, reinfection rather than relapse was probable because of the long interval between the end of treatment and follow-up and also because six of seven male consorts of these women were found to harbour $C$ trachomatis. These data suggest that the risk of chlamydia-infected women becoming reinfected is high.

Contact tracing was successful in only $26 \%$ of the 350 women who were advised to ask their partners to attend the STD clinic. This percentage is lower than in a recent study from Sweden, in which about twothirds of the male partners attended. ${ }^{2}$ The reason for this may be that the chlamydia-positive women in our series did not see a social worker who was specially trained in and responsible for contact tracing of patients with gonorrhoea and syphilis. The male consorts when attending the STD clinic may not have brought with them the written instruction that the patients should have given them. If so, these consorts would not have been identified from among other patients attending the STD clinic. Of the male consorts examined $53(58 \cdot 2 \%)$ harboured $C$ trachomatis, which agrees with that of other studies. ${ }^{2}$ In female partners of chlamydia-positive men the chlamydial isolation rate has varied between $62 \%$ and $68 \%$. $1020-22$

In women with signs of LGTI, particularly in the younger age groups, chlamydial isolation should be performed, since women with LGTI harbouring chlamydia present with the same symptoms as women in whom LGTI is not associated with chlamydia. Treatment of partners and contact tracing should both be carried out.

References

1. Persson K, Persson Kristina, Hansson $\mathrm{H}$ et al. Prevalence of nine different micro-organisms in the female genital tract. $\mathrm{Br}$. hu Vener Dis 1979;55:429-33.

2. Thelin I, Wennström A-M, Mårdh P-A. Contact-tracing inpatients with genital chlamydial infection. $\mathrm{Br} J$ Vener $\mathrm{DiS}$ 1980;56:259-62.

3. Mårdh P-A, Helin I, Bobeck S, Laurin J, Nilsson $T \vec{\omega}$ Colonisation of pregnant and puerperal women and neonateg with Chlamydia trachomatis. Br J Vener Dis 1980;56:96-100.0

4. Ripa T, Svensson L, Mårdh P-A, Weström L. Chlamydiă trachomatis cervicitis in gynecological outpatients. Obste Gynecol 1978; 52:698-702

5. Treharne J, Ripa T, Mårdh P-A, Svensson L, Weström L Darougar S. Antibodies to Chlamydia trachomatis in acutê
salpingitis. Br J Vener Dis 1979;55:26-9.

6. Mardh P-A, Lind I, Svensson L, Weström L, Mфller BO Antibodies to Chlamydia trachomatis, Mycoplasma hominis, and Neisseria gonorrhoeae in sera from patients with acute salpingitis. Br J Vener Dis 1981;57:125-9.

7. Waugh $M$, Nayyar K. Triple tetracycline (Deteclo) in the treatment of chlamydial infection of the female genital tracte Br J Vener Dis 1975; 53:96-7.

8. Ripa T, Mårdh P-A. Cultivation of Chlamydia trachomatis in cycloheximide-treated McCoy cells. J Clin Microbiof 1977; 5: 328-31.

9. Mårdh P-A, Mårtensson D, Soltesz L. An effective; simplified medium for the culture of Neisseria gonorrhoeae Sex Transm Dis 1978;5: 10-13.

10. Schachter J, Hanna L, Hill E et al. Are chlamydial infections the most prevalent venereal disease? JAMA 1975;231:1252-50

11. Schachter J, Causse G, Tarizzo M. Chlamydiae as agents oळ sexually transmitted diseases. Bull WHO 1976;54:245-52.

12. Paavonen J, Saikku P, Vesterinen E, Meyer B, Vartiainen EQ Saksela E. Genital chlamydial infections in patients attending gynaecological outpatient clinic. Br J Vener Dis 19789 54:257-61.

13. Jouppila P, Kivinen S, Korhonen S, Jokipii A. Chlamydiā trachomatis in gynecological outpatients. Duodecin 1978;94:972-7.

14. Oriel J, Johnson A, Barlow D, Thomas B, Nayyar K, Reeve $P(S)$ Infection of the uterine cervix with Chlamydia trachomatis. F Infect Dis 1978; 137:443-51.

15. Svensson L, Weström L, Ripa T, Mårdh P-A. Differences in some clinical and laboratory parameters in acute pelvi inflammatory disease related to culture and serologicab findings. Am J Obstet Gynecol 1980; 138suppl:903-22.

16. Hilton $A$, Richmond $S$, Milne J, Hindley $F$, Clarke $S$ Chlamydia $A$ in the female genital tract. $B r J$ Vener Dis 1974; 50: 1-10.

17. Tait A, Rees E, Hobson D, Byng R, Tweedie M. Chlamydia infection of the cervix in contacts of men with nongonococcaE. urethritis. Br J Vener Dis 1980;56:37-45.

18. Burns DCMac D, Darougar S, Thin R, Lothian L. Nicol CO Isolation of Chlamydia trachomatis from women attending clinic for sexually transmitted disease. $B r J$ Vener Dis 1975;51:314-8

19. Mårdh P-A, Colleen S, Sylwan J. Inhibitory effect on the formations of chlamydial inclusions in McCoy cells by semina fluid and some of its components. Invest Urol 1980; 17:510-30

20. Holmes $K$, Handsfield $H$, Wang SA et al. Etiology of none gonococcal urethritis. N Engl J Med 1975;292:1199-205.

21. Handsfield $\mathbf{H}$, Alexander $\mathbf{E}$, Wang SP, Pedersen $\mathbf{A}$, Holmes $\mathbf{K}_{-}^{-}$ Differences in the therapeutic response of Chlamydia-positive and Chlamydia-negative forms of nongonococcal urethritis. Am Vener Dis Assoc 1976; 2:5-9.

22. Paavonen J, Kousa M, Saikku $P$, Vesterinen $E$, Jansson $E^{\mathbb{D}}$ Lassus A. Examination of men with nongonococcal urethritiof and their sexual partners for Chlamydia trachomatis an Ureaplasma urealyticum. Sex Transm Dis 1978;5:93-6. 